\title{
New Insights for the Polypharmacy Use in Elderly with Diabetes-An Update about Effect of Education Level
}

\author{
Heverton Alves Peres1, ${ }^{*}$, Maria Cristina Foss de Freitas 1, Leonardo Régis Leira Pereira2 and Carlos Manuel Viana3 \\ ${ }^{1}$ Department of Internal Medicine, Ribeirão Preto Medical School, University of Sao Paulo, Ribeirão Preto, Sao Paulo, Brazil. \\ ${ }^{2}$ Department of Pharmaceutical Sciences, School of Pharmaceutical Sciences of Ribeirao Preto, University of Sao Paulo, \\ Ribeirao Preto, Sao Paulo, Brazil. \\ ${ }^{3}$ Viana Health Center, Aruba, Chine.
}

Received: November 27, 2017; Accepted: December 05, 2017; Published: December 11, 2017

*Corresponding author: Heverton Alves Peres, pharmacist and doctorate in medical clinical in Faculty of Medicine of Ribeirao Preto-SP, Brazil. Tel: +55 16-9215-4036;E-mail: haperes@usp.br

\section{Abstract}

Aim: To assess the effect of education diabetics in polypharmacy use and correlate with the scores of tests Medtake (MT), Diabetes Complications (DC) Morisky-Green (MGT) and pharmacotherapy complexity (PC).

Methods: We conducted a cross-sectional study and included diabetics attended done in basic Brazilian health unit. The patients were divided into two groups, one group being that takes less than five $(\leq 5)$ medicines and other that takes more than five $(>5)$ medicines. Then, we further separated the groups by education levels, basic and more advanced, and compared the results of the MT, MGT, DC and PC.

Results: The MT $(r=0.33$, p. $<0.00)$ and PC were positively correlated with less education in the patients that were taking $\leq 5$ medicines. Prescribed drug amounts $(\mathrm{r}=0.25, \mathrm{p} .<0.04)$, co morbidities $(\mathrm{r}=0.31, \mathrm{p} .<0.01)$, age $(\mathrm{r}=0.41, \mathrm{p} .<0.01)$ and $\mathrm{PC}(\mathrm{r}=0.65, \mathrm{p} .<0.00)$ were positive in patients with more education.

Conclusions: Clinically, diabetics with lower education levels have a poor knowledge of diabetic therapeutic and high pharmacotherapy complexity, contributing to higher co morbidities that influence a prescribed drug increase.

Keywords: Brazil; Diabetes Mellitus; Educational status; health education; polypharmacy

Abbreviations: MT: Medtake, MGT: Morisky-Green Test, DCI: Diabetes Complications Index, PC: Pharmacotherapy Complexity, T1DM: Type 1 Diabetes mellitus, T2DM: Type 2 Diabetes mellitus.

\section{Introduction}

Currently, the world population is quickly aging and taking multiple prescribed medications. Numerous prescribed drugs predispose diabetics to problems associated with druginteraction; adverse drug events and poor drug compliance. Polypharmacy, defined as the use of five drugs, or more $\geq 5$ presents in many patients with chronic diseases, especially diabetes. Clinical management of older diabetic adults may be further complicated with, co morbidities; advanced age; and micro vascular or macro vascular diabetic complications $[1,2]$.

One cohort study identified that $57 \%$ of diabetic patients with mean age $73.3 \pm 5.5$ years are using more than five pharmaceutical medicines [3]. This alarming situation reflects what exists in Brazil, where $20 \%$ of the oldest individuals use at least five medicines [4]. Since diabetic polypharmacy significantly increased treatment costs, it is in the public health interest to identify the factors driving up the necessity of multiple pharmaceutical prescriptions [5].

Known risk factors of polypharmacy use among diabetics include: multiple co morbidities and advanced age. Because, in Brazil, there is no monitoring of doctors' prescription rate of overprescribing or under-prescribing prescriptions; there are barriers associated with polypharmacy [6]. Appropriate prescribing is a challenge to health care providers treating older individuals, because polypharmacy is linked to: adverse drug events; multi-drug interaction; risk associated with noncompliance, where the side effects could be misinterpreted as new medical conditions, resulting in even more prescription [7]. Thus, patient follow-up, checking for drug interactions, and checking for medication usage compliance, are strongly recommended [8].

Despite all evidences about the effect of polypharmacy in Brazilians patients, few studies have explored the role of education level of diabetics in the polypharmacy. This absence in the literature is an open door to explore others factors that may influencing multi-drug use among those who have negligible knowledge about their prescription drugs. Lack of knowledge about their medication among diabetics inhibits compliance, increases the risk adverse multi-drug interaction, and increases, both, DC and PC [1, 2-8].

The MT is an instrument for assessing the knowledge of the patient about drugs taken. Our hypothesis is that the patients 
with higher education levels would have better (MT) scores, and have lower DC and PC.

Based on the background presented, this study proposed to investigate the impact of achieved education levels of diabetics with the polypharmacy in a basic Brazilian health unit. In this sample population, we also explored the association between: MT, Morisky- MGT, DC and PC.

\section{Methods}

This cross-sectional study was conducted in a municipality in the Brazilian state of São Paulo, Franca, Brazil. The STROBE Statement was followed in this study and we included all adult patients with T1DM and T2DM that were in the basic health unit during August 2017. In Brazil, primary care (PC), also called basic care (BC), is the preferential access method for the population to Sistema Único de Saúde (SUS) [Unified Health Services] services that over sees the organization and integration of Brazilian healthcare networks.

\section{Inclusion Criteria}

The inclusion criteria included a T2DM and T1DM diagnosis, both genders; aged from 18 to 90 years old; using isophane insulin (NPH) or Regular insulin; taking five or more $\geq 5$ prescribed medications; and either basic or more advanced education levels.

Clinical parameters, variables for factual data, including: fasting blood glucose, non-fasting, postprandial, amount of blood glucose levels, glycemic; and glycated hemoglobin (HbA1c) during the last six months were collected from medical records. All individuals who met the inclusion criteria were invited to sign the Free and Informed Consent Terms.

\section{Exclusion criteria}

The exclusion criteria included all patients without medical records of $\mathrm{HbA1c}$; pregnant women; cognitive deficit individuals and/or mental disorders; chronic diseases of greater complexity (kidney disease for example) and Illiterate patients.

\section{Data Collection}

All data was collected by one research using a questionnaire that was evaluated and standardized by twenty patients to correct differences of language interpretation. These volunteers were excluded from analysis. A questionnaire consisting of open questions was applied to all patients by attained researcher.

The patients were selected before medical consultation. Interviews were performed in a room separated from the doctor's office and the average time of each interview was 20 minutes. The variables collected through the questionnaire were gender, age, per capita income, marital status, schooling, co morbidities, time since diabetes diagnosis, number of drugs taken, consultation duration, drug loads, waist circumference (WC), body mass index (BMI), levels of fasting blood glucose, postprandial glucose, and glycated hemoglobin.

To evaluate the adherence to treatment, the patient's knowledge of the drugs in use, the complexity of pharmacotherapy, the complications of diabetes and number of insulin injections missed, the following tests were applied: DC, MGT, MT, AutoCompliance Test (ACT) and CP.

The DC is an instrument composed of 17 questions for analyzing the complications related to diabetes. Thus, five questions evaluate coronary heart disease, three questions for stroke, two questions for peripheral vascular disease, two questions for neuropathy, three questions for problems with the feet, and two questions for diabetic retinopathy [9]. Each complication is determined by two or more questions, for example, coronary heart disease is present if the patient reported having a myocardial infarction, symptoms of angina pectoris, or having been diagnosed by a doctor. The CDI calculates the sum of any complications that are present, resulting in scores from 0 to 6 .

The adherence to treatment was assessing by instrument MGT. Six questions with Yes/No answers were included in the MGT: (1) Have you ever forgotten to take your medicine for diabetes? (2) At times, are you not careful about taking your medicine for diabetes? (3) When you feel better, do you sometimes stop taking your medicine?(4) At times, if you feel worse when you take your medicine, do you stop taking it? (5) Do you know the long-term benefits of taking your medicine? (6) At times do you forget to replace your medicine before it finishes? The patient only answers questions five and six if he answers yes to all of questions one to four. The patients with scores of $\geq 80 \%$ in the MGT were considered as adherent [10].

The MT is an instrument for assessing the knowledge of the patient about drugs taken. The MT scores are calculated for each drug as the percentage of correct actions and compared with label directions of medications. This test evaluates dosage (units), indication, regime, and knowledge about the drug-interaction or food-drug interaction of medications being taken The MT has scores from 0 to $100 \%$ and the mean of all test scores for each patient is calculated, assessing the ability of subjects to take their drugs safety. Patients who correctly answered correctly the four questions have a score of $100 \%$ and patients who answered only three questions receive a score of 75\% [11].

The number of insulin injections missed in the previous months was assessed by ACT. This method assesses patient's self reporting of the difficulty of applying the insulin by asking two open questions: (1) "Did you have any difficulties in insulin injection?" and (2)"How many times did you skip insulin injection in the last month?" The AM was calculated using the following formula:

\section{Total number of insulin injections x 100}

\section{Total number of prescribed insulin injections}

Considered as compliant with insulin were the patients who affirmed taking more than $80 \%$ of the total of number of prescribed insulin injections [12].

The CPI is an instrument for assessing the effect of complexity of pharmacotherapy. This instrument is divided into three sections: A, B and C. The CPI is obtained by the sum of scores 
of the three sections. High section scores are defined as greater complexity [13].

The drug loads were calculated using the ATC/DDD system that serves as a tool for drug utilization research in order to improve the quality of drug use [14]. The basis of this system is the presentation and comparison of drug consumption statistics at international and other levels. The dose of drugs that the patient was taking was divided by defining the daily dose according to international drug utilization research. When the patient takes more of one drug, the ATC/DDD ratio values are increased. Patients with high values of drug loads have an overload in treatment and a high probability of developing adverse effects.

\section{Ethical considerations}

This study was part of a project entitled "Diabetes: Factors associated in the glycemic control" which was registered in Research Ethics Committee of the School of Medicine of Ribeirão Preto, University of São Paulo, protocol No.7724/2015 and release No. 2941 CEP/FMRP; rulingNo.049698/2015;CA EE45668815.9.0000.5440.

\section{Statistics}

The patients were initially divided into two groups: one group taking until five $(\leq 5)$ medicines and the other group taking more than five $>5$ pharmaceutical prescription medications. Data about the completed education level was self-reported. Then, the groups were further divided by education levels. The primary investigation of this study was to compare achieved education level and the amount of prescriptions being used. The next level search included correlating number of pharmaceutical drugs used with the research tools: MT; MGT; DCI and PCI.

Statistical analyses were performed using The Statistical Package for the Social Sciences (SPSS 18). We reported clinical and demographics variables as descriptive statistics in Tables 1 and 2. Correlations were performed using Pearson's correlation coefficient (r) to measure of the strength of the association between two linear relationship variables or the Spearman test, to measure of the strength of a monotonic relationship between paired data. The Spearman $p$ values set at $<0.05$ were considered statistically significant.

Logistic regression analyses were used to assess the relation of number of pharmaceutical drugs used by both groups (the dependent variable) with independent variables being: co morbidities, PC, prescribed drug amounts, HB1Ac levels, schooling levels, age and the MT.

\section{Results}

At baseline, 301 patients were included in the sample. The group with high school had more people taking less medicines compared to the group of low schooling (Table 1). Significant differences were found in the variables drug load $(1.9 \pm 0.97$ vs. $1.6 \pm 0.65$, p. $<0.05)$, co morbidities ( $3.4 \pm 2.8$ vs. $2.5 \pm 2.1$, p. $<0.02)$, amount of medication ( $3.85 \pm 1$ vs. $3 \pm 1.1$, p. $<0.00)$, PC $(15 \pm 3.5$ vs. $13.4 \pm 2.9$, p. $<0.01), \mathrm{DC}(2.1 \pm 1.3$ vs. $1.4 \pm 1.3, \mathrm{p} .<0.00)$, age $(62.5 \pm 11.4$ vs. $47 \pm 19$, p. $<0.00)$ of patients with less education compared to patients with more education. However, for the group that taking $>5$ medicines, we found significant differences only in age $(65.5 \pm 9.3$ vs. $57 \pm 12$, p. $<0.00)$ in the diabetics with less education compared to those with more education (Table 2).

The MT ( $r=0.33, \mathrm{p} .<0.00)$ and PC $(r=0.53, \mathrm{p} .<0.00)$, were positively correlated with less education in diabetics that taking until $\leq 5$ medicines. However, there was a positively correlation in the drug loads ( $\mathrm{r}=0.25, \mathrm{p} .<0.04)$; co morbidities ( $\mathrm{r}=0.31$, $\mathrm{p} .<0.01)$; age $(\mathrm{r}=0,41, \mathrm{p} .<0.01), \mathrm{CP}(\mathrm{r}=0.65, \mathrm{p} .<0.00)$ with more education in this group (Table 3 ).

\begin{tabular}{|c|c|c|c|c|}
\hline Variables & $\leq 5$ medicines $(n=135)$ & $>5$ medicines $(n=166)$ & OR & $\mathbf{P}$ \\
\hline$\leq 9$ years & 76 & 133 & \multirow{2}{*}{$0.31(0.19-0.53)$} & \multirow{2}{*}{$<0.00 *$} \\
\hline$>9$ years & 59 & 33 & & \\
\hline
\end{tabular}

Table 2 Clinical dates of according with schooling level

\begin{tabular}{|c|c|c|c|c|}
\hline \multirow[b]{2}{*}{ Variables } & \multicolumn{2}{|c|}{$\leq 5$ medicines } & \multirow[t]{2}{*}{ CI } & \multirow[t]{2}{*}{$\mathbf{P}$} \\
\hline & $\leq 9$ years $(n=76)^{a}$ & $>9$ years $(n=59)^{b}$ & & \\
\hline $\mathrm{Hb} 1 \mathrm{Ac} \%$ & $8.7 \pm 2.2$ & $8.9 \pm 2.5$ & $8.2-9.2^{\mathrm{a}} 8.1-9.6^{\mathrm{b}}$ & 0.71 \\
\hline Drug load & $1.9 \pm 0.97)$ & $1.6 \pm 0.65$ & $1.7-2.1^{\mathrm{a}} 1.4-1.7^{\mathrm{b}}$ & $<0.05^{*}$ \\
\hline Co morbidities & $3.4 \pm 2.8$ & $2.5 \pm 2.1$ & $2.9-3.8^{\mathrm{a}} 2-3^{\mathrm{b}}$ & $<0.02^{* *}$ \\
\hline MGT & $78 \pm 21$ & $76 \pm 17$ & $73-83^{\mathrm{a}} 72-81^{\mathrm{b}}$ & 0.43 \\
\hline MT & $58.7 \pm 21$ & $60 \pm 21$ & $53.8-63^{\mathrm{a}} 54-65^{\mathrm{b}}$ & 0.89 \\
\hline Amount of medications & $3.85 \pm 1$ & $3 \pm 1.1$ & $3.6-4^{\mathrm{a}} 2.8-3.4^{\mathrm{b}}$ & $<0.00^{* *}$ \\
\hline $\mathrm{PC}$ & $15 \pm 3.5$ & $13.4 \pm 2.9$ & $14-15.7^{\mathrm{a}} 12.6-14^{\mathrm{b}}$ & $<0.01^{* *}$ \\
\hline
\end{tabular}


New Insights for the Polypharmacy Use in Elderly with Diabetes-An

\begin{tabular}{|c|c|c|c|c|}
\hline DC & $2.1 \pm 1.3$ & $1.4 \pm 1.3$ & $1.8-2.4^{\mathrm{a}} 1-1.8^{\mathrm{b}}$ & $<0.00^{* *}$ \\
\hline Age (years) & $62.5 \pm 11.4$ & $47 \pm 19$ & $59.8-65^{\mathrm{a}} 42-52^{\mathrm{b}}$ & $<0.00^{* *}$ \\
\hline \multirow[t]{3}{*}{$\mathrm{BMI} \mathrm{kg} / \mathrm{m}^{2}$} & $28.8 \pm 5.2$ & $27.9 \pm 5.6$ & $27.8-30^{\mathrm{a}} 26-29.5^{\mathrm{b}}$ & 0.37 \\
\hline & \multicolumn{2}{|c|}{$>5$ medicines } & & \\
\hline & $\leq 9$ years $(n=133)_{-}^{a}$ & $>9$ years $(n=33)^{b}$ & & \\
\hline $\mathrm{Hb} 1 \mathrm{Ac} \%$ & $9 \pm 1.8$ & $9.2 \pm 1.4$ & $8.8-9.4^{\mathrm{a}} 8.5-9.7^{\mathrm{b}}$ & 0.78 \\
\hline Drug load & $2.1 \pm 0.8$ & $2 \pm 0.8$ & $2-2.3^{\mathrm{a}} 1.8-2.4^{\mathrm{b}}$ & 0.95 \\
\hline Co morbidities & $4.9 \pm 1.7$ & $5.1 \pm 1.8$ & $4.6-5.2^{\mathrm{a}} 4.5-5.8^{\mathrm{b}}$ & 0.57 \\
\hline MGT & $79 \pm 18$ & $75 \pm 19$ & $75-82^{\mathrm{a}} 68-81.8^{\mathrm{b}}$ & 0.28 \\
\hline MT & $61 \pm 19$ & $60 \pm 18$ & $58-64^{\mathrm{a}} 54-67^{\mathrm{b}}$ & 0.93 \\
\hline Amount of medications & $7.8 \pm 1.6$ & $7.9 \pm 1.8$ & $7.5-8^{\mathrm{a}} 7.3-8.6^{\mathrm{b}}$ & 0.64 \\
\hline PC & $22.5 \pm 5.2$ & $21 \pm 5$ & $21.5-23^{\mathrm{a}} 19.6-23^{\mathrm{b}}$ & 0.38 \\
\hline DC & $2.7 \pm 0.8$ & $2.5 \pm 1.2$ & $2,5-2.9^{\mathrm{a}} 2-3^{\mathrm{b}}$ & 0.53 \\
\hline Age (years) & $65.5 \pm 9.3$ & $57 \pm 12$ & $64-67^{\mathrm{a}} 52-61.6^{\mathrm{b}}$ & $<0.00^{* *}$ \\
\hline $\mathrm{BMI} \mathrm{kg} / \mathrm{m}^{2}$ & $31 \pm 5.5$ & $33.5 \pm 6.5$ & $30-32^{\mathrm{a}} 31-35^{\mathrm{b}}$ & $<0.05^{*}$ \\
\hline
\end{tabular}

Legends: MGT, Morisky-Green Test, MT, Medtake test, CPI, Complexity of Pharmacotherapy Index, CPI, Complications Diabetes Index.

Table 3: Correlations between variables of both groups separated by schooling levels

\begin{tabular}{|c|c|c|}
\hline \multirow[b]{2}{*}{ Variables } & \multicolumn{2}{|c|}{$\leq 5$ medicines } \\
\hline & $\begin{array}{c}\leq 9 \text { years }(n=76) \\
\text { r(p-value) }\end{array}$ & $\begin{array}{c}>9 \text { years }(n=59) \\
r(p \text {-value })\end{array}$ \\
\hline $\mathrm{Hb} 1 \mathrm{Ac}$ & $-0.18(0.11)$ & $0.45(0.75)$ \\
\hline Drug load & $0.06(0.95)$ & $0.25(<0.04 *)$ \\
\hline Co morbidities & $0.18(0.11)$ & $0.31(<0.01 *)$ \\
\hline Age & $-0.43(0,70)$ & $0.41(<0.01 *)$ \\
\hline MGT & $0.10(0.36)$ & $-0.07(0.56)$ \\
\hline CDI & $0.08(0,47)$ & $0.19(0.14)$ \\
\hline MT & $0.33\left(<0.00^{* *}\right)$ & $0.10(0.94)$ \\
\hline \multirow[t]{4}{*}{ PC } & $0.53\left(<0.00^{* *}\right)$ & $0.65\left(<0.00^{* *}\right)$ \\
\hline & \multicolumn{2}{|c|}{$>5$ medicines } \\
\hline & $\leq 9$ years $(n=133)$ & $>9$ years $(n=33)$ \\
\hline & r(p-value) & r(p-value) \\
\hline $\mathrm{Hb} 1 \mathrm{Ac}$ & $0.01(0.93)$ & $-0.16(0.94)$ \\
\hline Drug load & $0.17\left(<0.05^{*}\right)$ & $0.29(0.10)$ \\
\hline Co morbidities & $0.49\left(<0.00^{* *}\right)$ & $0.17(0.34)$ \\
\hline Age & $-0.24(0.78)$ & $0.78(0.66)$ \\
\hline MGT & $0.09(0.25)$ & $-0.20(0.27)$ \\
\hline CDI & $0,32\left(<0.00^{* *}\right)$ & $0,43\left(<0.01^{*}\right)$ \\
\hline MT & $0.01(0.92)$ & $-0.21(0.90)$ \\
\hline CPI & $0.80\left(<0.00^{* *}\right)$ & $0.90\left(<0.00^{* *}\right)$ \\
\hline
\end{tabular}


For the group that taking $>5$ medicines, there was positively correlation in the drug load $(\mathrm{r}=0.17$, p. $<0.05)$; co morbidities $(\mathrm{r}=0.49, \mathrm{p} .<0.00)$, DC $(\mathrm{r}=0.32, \mathrm{p} .<0.00)$; $\mathrm{PC}(\mathrm{r}=0.80, \mathrm{p} .<0.00)$ in the diabetics with less education. In the diabetics with more education, there was positively correlation in the variables DC ( $\mathrm{r}=$ 0.43 , p. $<0.01)$ and PC (r=0.90, p. <0.00).

Besides that, logistic regression analysis showed that there was an association with MT $(\beta=0,267, p .<0.02)$ and $P C(\beta=0.444$, $\mathrm{p}<0.00$ ) with diabetics that taking $\leq 5$ medicines with less education (See in our supplementary material). In contrast, age $(\beta=0.395, p .<0.04)$ and $P C(\beta=0.607, P .<0.00)$ were associated in the diabetics with more education.

For the diabetics that taking $>5$ medications, the co morbidities $(\beta=0.237$, p. $<0.00)$, MGT $(\beta=0.173$, p.<0.02), PC $(\beta=0,721, p .<0.00)$, were associated with less education. For the diabetics with more education, there was association with PC $(\beta=0.838$, p. $<0.00)$.

\section{Discussion}

Clinically, our findings contribute to the current literature by describing that less education in diabetics taking until $\leq 5$ medicines was associated the little retained information about diabetic treatments and high pharmacotherapy complexity. However, those diabetics with more education were associated with lower age and low pharmacotherapy complexity. In this baseline, our work is one of the few in the literature addressing this gap between role level of education and polypharmacy in the Brazilian population.

Diabetic patients taking more five medicines, the high pharmacotherapy complexity, more co morbidities and low scores in the MGT and were associated with lower education levels. However, low pharmacotherapy complexity scores were associated with diabetics with more education. In this baseline, the low scores in the MT added to the PC scores among diabetics with less education influence the numbers of medications used. Diabetics with more education have lower prescribed drug amounts, co morbidities and pharmacotherapy complexity scores. Diabetics with less education take more medicines and have more pharmacotherapy complexity compared to diabetics with more education (Table 2).

We confirmed our initial hypothesis - that diabetics with more education that use at least five medicines have better scores in the MT, lower DC and PC scores, but had worse glycemic control. Higher fasting glucose and hba1c levels may be occurring because of longer period with diabetes, contributing to patients' obesity and co morbidities. All patients in the higher education group have higher than recommended values and diabetics diagnosed with diabetes for more than fifteen years did not achieve optimum hba1c target $[15,16]$.

Our findings confirmed that elderly diabetic patients that have been diagnosed with diabetes for a long time; are female; simultaneously present with more chronic diseases than diabetes, co morbidities; and a having a body mass index $\geq 30$ $\mathrm{kg} / \mathrm{m} 2$ and are associated with polypharmacy. In our study, all patients are overweight of according to established guidelines, and the obesity appears to be a factor of increase drug use $[5,6]$. We demonstrated that there is a positive correlated between: prescribed drug amounts; age; co morbidities; and CPI scores. Thus, higher education levels with diabetic patients contribute to fewer prescribed drug amounts, co morbidities and pharmacotherapy complexity.

Less educated diabetics are hampered to achieve improved health outcomes. Appreciating the relationship between lower education grades realized and polypharmacy is a critical public health realization. Lately, there is only one systematic review addressing the issue of education level's influence on medicine use; and there were no randomized trials aimed at improving diabetics' health knowledge. In this review, consistent results of eight studies suggested a positive association between heath information and diabetes knowledge. However, the authors reported that current understanding of the effect of less education completed in diabetics needs to be addressed in future studies [17]. Given the crucial nature of this topic, we were surprised with by the lack of studies addressing these issues; especially, the prevalent relationship of older diabetics taking five or more $\geq 5$ medicines. Additionally, not addressed is the association of higher education levels achieved with low diabetes complications and pharmacotherapy complexity in the diabetics taking more than five medicines.

Looking for a solution by increasing the number of doctors is irrelevant if we do not change the current Brazilian medical model. There is no point in throwing money at the problem, because the increased financial burden to the Brazilian public health system will not improve the quality of life of those patients most affected. In the Brazilian public health system, the time spent in a consultation is usually, most of the time, less than ten minutes $[1,2]$. Usually, doctors only changes the prescription or increases the dose of the medicine; increasing the negative side effects of polypharmacy.

Chronic diseases like Diabetes are better managed when there exists: a committed patient; relevant medical care and the health team involvement. In this baseline, we appreciate the relevance of patient diabetes and medication education as a powerful tool. Noted is that as pharmaceutical care improves there is increased treatment compliance; decreased side effects; and reduced pharmacotherapy complexity. If these suggestions were to be implemented, patients with diabetes, or any chronic diseases, may avoid iatrogenic problems, other illness caused by medicine or treatment, avoiding unnecessary hospitalizations [18].

We recommend graphic stories in fourth grade Portuguese or other language be developed to provide more diabetes information, what constitutes better diabetic patient care and education on prescription medication. Although picture drawings, comic book scan contain, simplified written accounts of illness, their powerful visual messages convey immediate intuitive understanding in ways that conventional texts cannot. Additionally, comic books shared with young patient's family members within the family can develop supportive resources. Besides that, factors like as toxins, stress, infections, malnutrition and electromagnetic pollution should be investigate in the 
diabetes besides of and family social support, what contribute for better glycemic control [19,20-22]. Sir Muir Gray, Director United Kingdom's National Knowledge Service said "Knowledge is the enemy of disease, the application of what we know will have a bigger impact than any drug or technology likely to be introduced in the next decade."

Limitations, once again is since our study was designed as an exploratory endeavor, it might not be exempt from causality inferences or, possible biases that affect the resulting values. (recall bias in relation to medicines). First, the reproducibility of our findings should be confirmed within other Brazilian basic health units, so as the impact of using Medtake test (MT) in the diabetics less education burdened with polypharmacy can be educated about pharmacotherapy reducing the pharmacotherapy complexity. Second, this study was conducted in a single health unit, so the generalization of data should be performed with caution. Finally, self-reporting generally tends to yield inflated estimates in the MT, MGT; CDI and CPI and could have been somewhat lower than we observed. However, even though selfreporting has been criticized as an excessively subjective and upwardly-based approach to estimating, we feel the findings of Aikens and Piette analysis strengthen their use of self-reporting in evaluating a diabetic patient [21]. In fact, our study had few patients with more education in both groups, but still we found significant differences However, we are still cautious due to sample size. Yet the tests MT, MGT show validation of our hypothesis.

\section{Conclusions}

The education of patient with diabetes increase practical knowledge about diabetic therapy reducing the public health costs besides of DC and PC. Diabetics with less education have high diabetes complications and pharmacotherapy complexity, low adherence and poor knowledge of pharmacotherapy contributing to poor glycemic control while diabetics with more education take less prescribed medicines, fever pharmacotherapy complexity, and better control of diabetes complications. From our findings, we encourage randomized trials addressing results of education efforts implemented with diabetic patient. The education aim is to increase their practical knowledge about their therapeutic regimen; reduce diabetes complications and pharmacotherapy complexity; thus lowering the risk of iatrogenesis and reducing public health costs.

\section{References}

1. Peres HA, Freitas MCF, Pereira LRL. Low scores in Auto-Compliance Method and Fast Medical Care influence the poor adherence in diabetics attended in the basic health unit. Biol Med. 2017;9:1-8.

2. Peres HA, Martinez EZ, Pereira LRL, Freitas, MCF. Age, the Number of Medicines Taken and Co morbidities are Associated with Changes of Fasting Blood Glucose Levels in Elderly Diabetics Taking Propranolol and Hydrochlorothiazide. J Bioanal Biomed. 2017;9:240-243. Doi: 10.4172/1948-593X.1000186

3. Noale M, Veronese N, Cavallo Perin P, Pilotto A, Tiengo A, Crepaldi G, et al. Polypharmacy in elderly patients with type 2 diabetes receiving oral ant diabetic treatment. Acta Diabetol. 2016;53(2):323-330. Doi: 10.1007/s00592-015-0790-4

4. Ramos LR, Tavares NUL, Bertoldi AD, Farias MR, Oliveira MA, Luiza VL, et al. Polypharmacy and Polymorbidity in Older Adults in Brazil: a public health challenge. Rev.Saúde de Pública. 2016;50(suppl 2):9. Doi: 10.1590/S1518-8787.2016050006145

5. Carvalho MFC, Romano-Lieber NS, Bergsten-Mendes G, Secoli SR, Ribeiro E, et al. Polifarmácia entre idosos do Município de São Paulo Estudo SABE. Rev. Bras. Epidemiol. 2012;15(4):817-827.

6. Peron EP, Ogbonna KC, Donohoe KL. Ant diabetic Medications and Polypharmacy. Clin Geriatr Med. 2015;31(1):17-27. Doi: 10.1016/j. cger.2014.08.017

7. Rochon PA, Gurwitz JH. Optimising drug treatment for elderly people: the prescribing cascade. BMJ.1997;315(7115):1096-1099.

8. Peres HA, De Castro, SHR. Tratamento farmacológico e interações medicamentosas em pacientes com aneurisma da aorta abdominal. Infarma. 2015;27(2):135-141. Doi: 10.14450/2318-9312. v27.e2.a2015.pp135-141

9. Fincke BG, Clark JA, Linzer M, Spiro A, Miller DR, et al. Assessment of long-term complications due to type 2 diabetes using patient selfreport: the diabetes complications index. J Ambul Care Manage. 2005;28(3):262-273.

10. Morisky DE, Green LW, Levine DM. Concurrent and Predictive Validity of a Self-Reported Measure of Medication Adherence. Med Care. 1986:24(1):67-74.

11. Raehl CL, Bond CA, Woods T, Patry RA, Sleeper RB. Individualized drug use assessment in the elderly. Pharmacotherapy. 2002;22(10):12391248.

12. Farsaei S, Radfar M, Heydari Z, Abbasi F, Qorbani M. Insulin adherence in patients with diabetes: risk factors for injection omission. Prim Care Diabetes.2014; 8(4):338-345.

13. Melchiors AC, Correr CJ, Fernández-Llimos F. Translation and validation into Portuguese language of the medication regimen complexity index. Arq Bras Cardiol. 2007;89(4):210-218.

14. International language for drug utilization research. 2017.

15. Spann SJ, Nutting PA, Galliher JM, Peterson KA, Pavlik VN, et al. Management of type 2 diabetes in the primary care setting: a practicebased research network study. Ann Fam Med. 2006;4(1):23-31. Doi: $10.1370 / \mathrm{afm} .420$

16. Baptista DR, Thieme RD, Reis WCT, Pontarolo R, Correr CJ. Proportion of Brazilian diabetes patients that achieve treatment goals: implications for better quality of care. Diabetol. Metab Syndr. 2015;7:113. Doi: 10.1186/ s13098-015-0107-3

17. Al Sayah F, Majumdar SR, Williams B, Robertson S, Johnson, JA. Health literacy and health outcomes in diabetes: a systematic review. Journal of General Internal Medicine. 2013;28:444-452. Doi: 10.1007/s11606012-2241-z

18. Borges APDS, Guidoni CM, Ferreira LD, Freitas O, Pereira LRL(2010). The Pharmaceutical care of patients with type 2 diabetes mellitus. Pharm World Sci. 2010; 32(6):730-736.

19. Peres HA, Pereira LRL, Freiras MCF. Toxins, Malnutrition, Stress, Infections and Electromagnetic Pollution: Looking about New Perspectives in Development of Diseases. J Nutr Food Sci. 2016;6:1-7.

20. Gomes LC, Coelho ACM, Santos GD, Freitas MCF, Pace, AE. Contribution of family social support to the metabolic control of people with diabetes mellitus: A randomized controlled clinical trial. Applied Nursing Research. 2017;36: 68-76. Doi: 10.1016/j.apnr.2017.05.009

21. Aikens JE, Piette JD. Longitudinal association between medication adherence and glycemic control in Type 2 diabetes. Diabet Med. 2013;30:338-344. Doi: 10.1111/dme.12046

22. Sue Kirkman M, Briscoe VJ, Clark N, Florez H, Haas LB, et al..Diabetes in Older Adults: A Consensus Report. J. Am. Geriatr. Soc. 2012; 60(12):2342-2356. Doi: 10.1111/jgs.12035 